\title{
THE DOMAŠA RESERVOIR IN THE SPECTRUM OF CLIMATE CHANGE
}

\author{
Juraj ŠKVARKA ${ }^{1 *}$, Emília BEDNÁROVÁ1', Marián MIŠČíK², L'ubomír UHORŠČÁK
}

\section{Abstract}

The importance of water reservoirs in the uneven distribution of discharges over time and space does not need to be explicitly justified. There is a more than 6,000-year history of convincing evidence. In Slovakia, the construction of reservoirs can be dated to two periods. The first period was the 18th century, when the construction of water reservoirs was stimulated by the need for water for the mining industry in the vicinity of the town of Bánska Štiavnica. The second period falls into the second half of the 20th century. The construction of reservoirs was initiated by the post-war period, including the need to increase society's standard of living, the electrification of the region, the development of industry and agriculture, flood protection, etc. Reservoirs with multi-annual regulations have an essential position in the types of water reservoirs. While small water reservoirs and annual or seasonal regulation can regulate flows in a short period, reservoirs with multi-annual regulation can regulate flows over several years. This benefit is evident, especially during periods of extreme hydrological phenomena and short-term aquatic and long-term dry, so-called low water periods. We have illustrated our knowledge of and experience gained from their impact on the flows downstream of the Vel'ká Domaša dam. We analyzed two time periods, i.e., before and after the year 2000. The influence of extreme hydrological phenomena on the runoff conditions downstream of the dam is presented by statistical processing of the available flow series

\section{Address}

1 Dept. of Geotechnics, Faculty of Civil Engineering, Slovak University of Technology in Bratislava, Slovakia

2 Slovenský vodohospodársky podnik, š. p., OZ Košice, Slovakia

3 Vodohospodárska výstavba, š. p., TBD Košice, Slovakia

* Corresponding author: juraj.skvarka@stuba.sk

\section{Key words}

- Reservoir,

- Dam,

- Climate,

- Discharge,

- Reliability

\section{INTRODUCTION}

The Vel'ká Domaša dam was built between 1962 and 1967. With a total original volume of 187.5 million $\mathrm{m}^{3}$, this reservoir was created by damming the valley of the river Ondava at the river kilometer 71.565 with a heterogeneous earth dam with an internal seal (Fig. 1).

However, the results of the reservoir's volume measurements in 1992 showed a decrease in its total volume to approx. $178.2 \mathrm{mil.} \mathrm{m}^{3}$; measurements in 2009 confirmed a further reduction in its total capacity to approx. $172.8 \mathrm{mil} . \mathrm{m}^{3}$. The reason for these changes lies not only in a more precise methodology for determining the reservoir's storage elevation curve, but also in the more accurate measurement of sediments in the reservoir compared to previous measurements. Their determining factor is primarily the geological and morphological composition of the affected environment. The flooded area is about $15.1 \mathrm{~km}^{2}$, and there is a backwater length of $13.5 \mathrm{~km}$ at the reservoir's maximum water level.

The geological environment of the hydraulic structure and its entire catchment area are characterized by the Paleogenic rocks (Magura flysch) and Quaternary sediments that determined the typology 


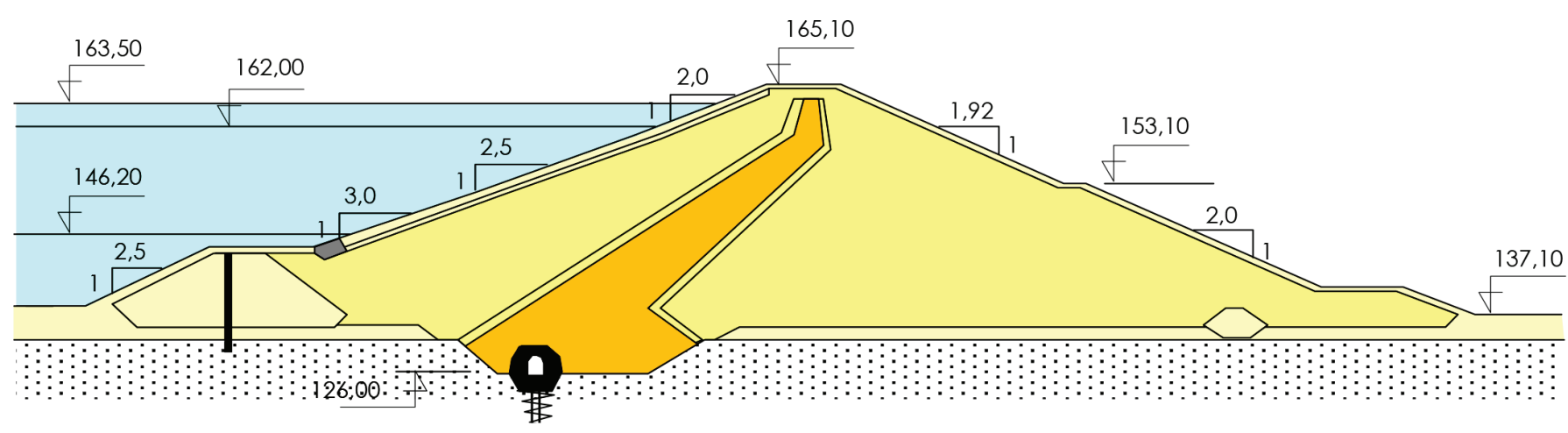

Fig. 1 Scheme of the cross-section of the Vel'ká Domaša dam

of the dam body, which is made of local materials. The scheme of its cross-section is depicted in Fig.1. The stabilizing prisms of the heterogeneous earth-fill dam with an internal inclined sealing were built of alluvial gravels. Sandy clays were used in the sealing, which is separated from the stabilizing prisms by a single-layer filter.

The dam's sealing is embedded in the bedrock by a wide sealing element and a concrete grouting gallery, from which a single-row grouting screen was built to a depth of 20 to $25 \mathrm{~m}$. The maximum height of the dam above the terrain is $25.4 \mathrm{~m}$ above the foundation joint, which is $35.0 \mathrm{~m}$. The upstream slope's inclination is variable, i.e., from $1: 2$ to $1: 3$, and the downstream's inclination is from $1: 1.92$ to $1: 2$. The dam's crest at the level of $165.10 \mathrm{~m}$ a.s.1. is $7.0 \mathrm{~m}$ wide. In the alluvial plain area, the body of the dam reaches a width of 166.7 $\mathrm{m}$. The volume of the local materials, i.e., alluvial gravels and sandy clays, built into the dam's body is about $660000 \mathrm{~m}^{3}$ (Bednárová et al., 2010). The functioning of the hydraulic structure is ensured by the intake structure and bottom outlets, which are grouped into an appurtenant structure and a spillway. Two intake canals provide withdrawals of the water to a power plant.

The bottom outlet is used to regulate the amount of water sent to the riverbed downstream of the dam. Its capacity is $Q=135.00$ $\mathrm{m}^{3} \cdot \mathrm{s}^{-1}$. A side, ungated spillway with a capacity of $\mathrm{Q}=358.60 \mathrm{~m}^{3} \cdot \mathrm{s}^{-1}$ is situated on the left bank of the reservoir. The hydroelectric power plant is situated in the alluvial plain valley at the foot of the dam's downstream slope. Two Kaplan turbines with a capacity of $2 \times 25 \mathrm{~m}^{3} \cdot \mathrm{s}$ ${ }^{1}$ were installed. It is a peak load hydropower plant. The currently required outflow influences the reservoir's guaranteed peak time and the storage volume (1.03 million $\left.\mathrm{m}^{3}\right)$ of the compensating Malá Domaša reservoir. Malá Domaša is part of the water management system and ensures the discharge regulation into the Ondava riverbed downstream of the system. Together with the geological conditions and the intense wave regime, the morphology of the reservoir banks creates the conditions for extensive wave abrasion and landslides around its perimeter. Therefore, the reservoir's banks damaged by abrasion have been stabilized in several sections by heavy stone riprap.

\section{LESSONS LEARNED FROM THE RESERVOIR'S OPERATION}

The reservoir's purpose was to create water storage to improve the flows downstream of the dam, supply industry and agriculture, produce electricity, and assure flood control for the valley downstream of the dam. An associated benefit of the reservoir is the development of recreation, water sports, and tourism in the affected area. Due to the significant fluctuation of the Ondava discharges $\left(\mathrm{Q}_{\max } / \mathrm{Q}_{\min }>500\right)$, suitable morphological conditions (accumulated volume/height of the dam) permitted the design of a reservoir with a multi-annual regulation cycle. The optimal ecological discharge was set at $\mathrm{Q}=5.91 \mathrm{~m}^{3} \cdot \mathrm{s}^{-1}$ during workdays, and $\mathrm{Q}=4.7 \mathrm{~m}^{3} \cdot \mathrm{s}^{-1}$ during weekends to ensure the above-mentioned functions. Later, irrigation water was no longer needed, and changes in the water management regime took place in 2003. As part of the operational regulations (in 2003 and later in 2013), the needed discharge value was reduced to $4.9 \mathrm{~m}^{3} \cdot \mathrm{s}^{-1}$. Respectively, due to the public and the state administration's pressure on the sustainability of the required water level in the reservoir for recreational purposes, it was reduced to $3.5 \mathrm{~m}^{3} \cdot \mathrm{s}^{-1}$ during winter operations. The values determined in this way were also confirmed by regulations prepared by the Water Research Institute in Bratislava (Benický, 2013), which state that the reservoir can provide $\mathrm{Q}_{\mathrm{opt}}=4.9 \mathrm{~m}^{3} \cdot \mathrm{s}^{1}$ with the current storage volume. The regulations also admit the possibility of a temporal reduction of discharges at $\mathrm{Q}_{\mathrm{opt} \text {, red }}=4.25 \mathrm{~m}^{3} \cdot \mathrm{s}^{-1}$ when the water level falls below $155.00 \mathrm{~m}$ a.s.l. or $\mathrm{Q}_{\mathrm{opt}}$, zs $=3.5 \mathrm{~m}^{3} \cdot \mathrm{s}^{-1}$, if the level falls below $152.00 \mathrm{~m} \mathrm{n}$. $\mathrm{m}$. However, except for the summer period, it would no longer be possible to ensure the water's good ecological status in the Ondava downstream of the reservoir with such reduced discharges. The operator's primary goal is to manage the water in the reservoir to avoid a hydrological deficit downstream of the dam and the ecological instability of the river.

In recent decades, climate change, extreme hydrological phenomena, and environmental protection have been the focus of discussions of experts and the public. In this context, various environmental measures have come to the fore as a tool for solving the negative impacts of short-term extreme flood discharges and long-lasting droughts. There is no doubt that rational forestry and agrotechnical measures, infiltration elements, green roofs, damming streams, and other measures are justified for average climatic events. However, the negative impact of extreme hydrological phenomena, i.e., floods and long-lasting droughts, cannot be prevented without significant technical measures, among which reservoirs have a unique place (Lukáč and Bednárová, 2001). This has also been confirmed by lessons learned from the period before 1950 when there were no huge reservoirs but only today so preferred forestry and agricultural measures in Slovakia. There were no reservoirs and dams, but there were cyclical floods, e.g., on the Orava River in the years $1725,1748,1749,1750$ to 1813 , $1830,1848,1870$, and on the Váh River in the years 1557, 1593, 1594 to $1602,1622,1625$ to $1710,1714,1813,1880,1950$ and 1960 . Their occurrence was only eliminated by the construction of water reservoirs such as on the Orava and Liptovská Mara and other technical flood control measures. Likewise, the important functions of water reservoirs' can be assessed, especially with multi-annual regulation, during periods of long-lasting droughts. In the presented paper, we demonstrate a connection with the protection of the environment within the reservoir's basic functioning, i.e., the so-called affected discharges of the Vel'ká Domaša dam. 


\section{RESULTS}

To evaluate the effect of the Vel'ká Domaša water reservoir on the hydrological regime of the runoff downstream of the dam, an analysis of the inflows and outflows is necessary. This analysis includes developmental trends of the time and water levels in the reservoir, but above all, the probability curve of the discharges, i.e., the reservoir inflows and outflows into the riverbed downstream of the dam. It is possible to assess a certain probability of exceeding the optimal ecological discharge without the affected discharges by processing hydrological data (Lukáč, 1997; Votruba and Patera, 1997). To assess the impact of climate change on the dam, which has been the subject of extensive discussions in our country since the late 1990s, we present a brief overview of an analysis focusing on two periods, i.e., the years 1976 to 1997 and 1998 to 2019 . The basis for the solution, i.e., inflows into the reservoir, was determined based on the development of the water levels in the reservoir during its actual operations and subsequently confronted with the measurements of the Slovak Hydrometeorological Institute (SHMÚ) at the Stropkov gauging station. Accordingly, it was possible to consider the inflow from the central catchment at a length of approximately $11 \mathrm{~km}$ between the SHMÚ gauging stations in Stropkov and the reservoir as well as other branches of the Ondava River (Olšavka, Brusnička, Vojtovec, and Kručovský stream), versus the streams directly flowing into the reservoir (Hrabovčík, Lomnianka, Valkovský, Surový, and Suchý streams, etc.). It is also possible to take into account losses due to evaporation from the water surface.

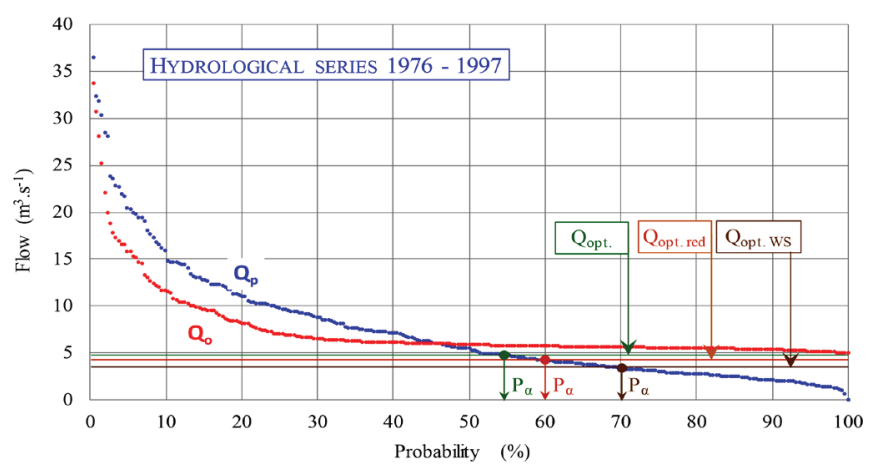

Fig. 2 Probability curve of the exceedance of the average monthly inflows and outflows at the Vel'ká Domaša dam (1976 - 1997)
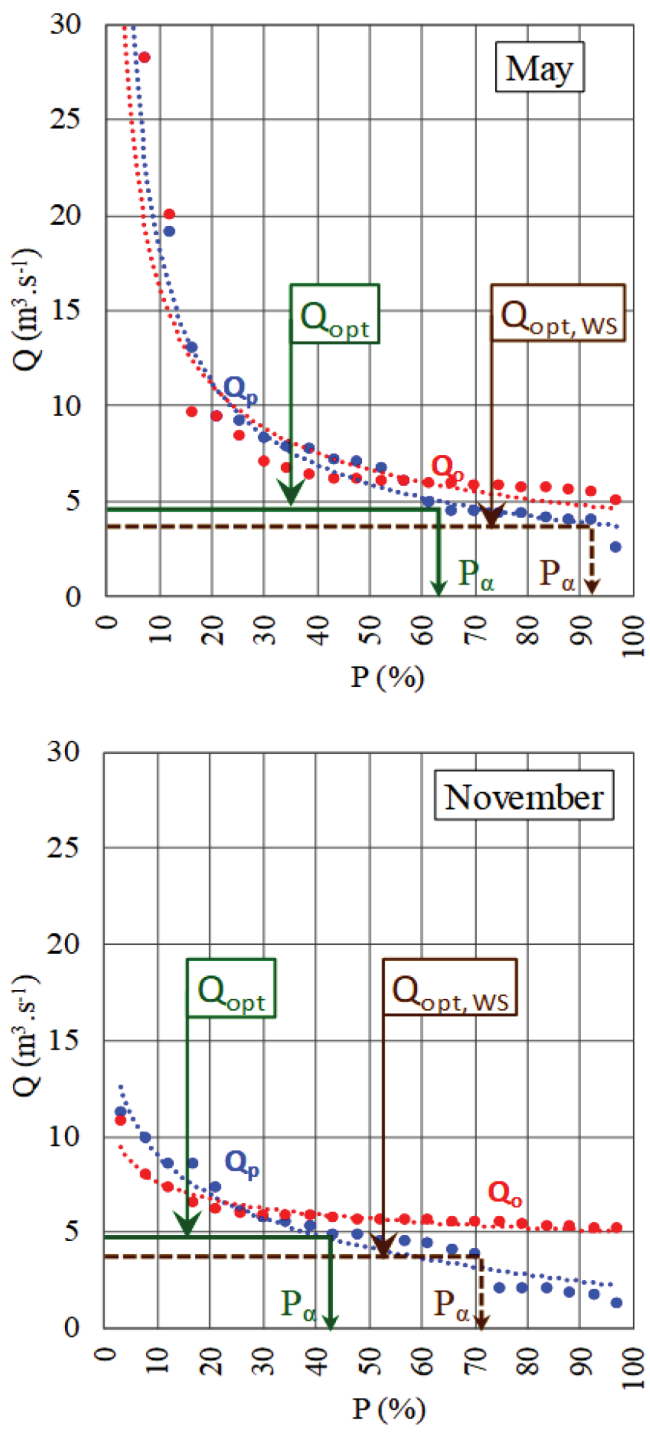
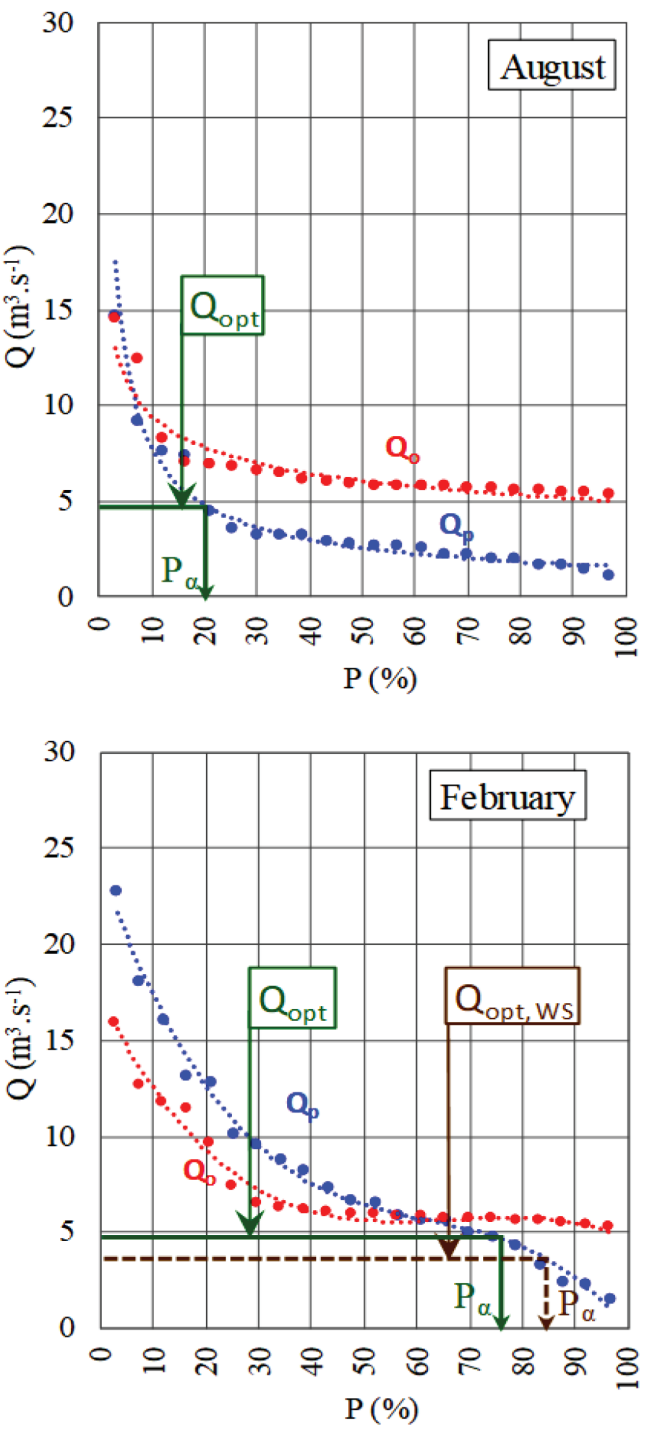

Fig. 3 The probability curves of the discharges for the average monthly inflows and outflows in the selected months for the period 1976-1997 


\subsection{6 - 1997 PERIOD}

The inflow and outflow of the hydrological conditions into the reservoir for the mentioned period are characterized by the probability curve of exceedance of the average monthly discharges (Fig. 2). There are processed dependences, i.e., $Q_{p}=f(P)$ and $Q_{o}=f(P)$, where $Q_{p}$ is the inflow to the reservoir; $Q_{o}$ is the outflow from the reservoir; and $\mathrm{P}$ is the probability of an occurrence. Simultaneously, in the picture, we can find the natural reliability of discharge $\mathrm{P} \alpha$ of the optimal ecological discharge $\mathrm{Q}_{\text {opt }}=4.9 \mathrm{~m}^{3} \cdot \mathrm{s}^{-1}$, reduced discharge $\mathrm{Q}_{\text {opt'red }}=4.25 \mathrm{~m}^{3} \cdot \mathrm{s}^{-1}$ at water level below $155.00 \mathrm{~m}$ a.s.1., and reduced discharge $\mathrm{Q}_{\mathrm{opt}}, \mathrm{zs}=3.5 \mathrm{~m}^{3} \cdot \mathrm{s}^{-1}$ at water level below $152.00 \mathrm{~m}$ a.s.l., outside the summer season (except the months from July to September). As the results of the analysis show, the natural reliability of the optimal ecological discharge from the Ondava is in a range from $55 \%\left(\right.$ for $\left.\mathrm{Q}_{\text {opt }}=4.9 \mathrm{~m}^{3} \cdot \mathrm{s}^{-1}\right)$ to $70 \%\left(\mathrm{Q}_{\mathrm{opt}} \mathrm{zs}=3.5 \mathrm{~m}^{3} \cdot \mathrm{s}^{-1}\right)$ in the area of the dam's profile. The reservoir's positive functioning is evident from the probability curve of the outflows, i.e., the redistribution of the discharges from the Ondava over time. It follows that the average monthly inflows to the reservoir higher than $6.0 \mathrm{~m}^{3} \cdot \mathrm{s}^{-1}$ with a probability of occurrence of about $45 \%$ were reduced and that inflows smaller than $6.0 \mathrm{~m}^{3} \cdot \mathrm{s}^{-1}$ with a probability of occurrence of about $55 \%$ have been improved. Following the operational rules, approximately $5.0 \mathrm{~m}^{3} \cdot \mathrm{s}^{-1}$ of the water was discharged into the Ondava riverbed downstream of the dam to ensure an optimal ecological discharge. The positive impact of the reservoir's operations, which consist of the unbalanced discharge redistribution in the Ondava, is documented by the ecologically optimal outflow conditions downstream of the dam.

However, it is not clear from the analysis presented how the fluctuations of flows affect the river's ecological stability during the year. The assessment of the hydrological conditions of the Ondava River and the demonstration of the reservoir's influence on the runoff downstream from the dam during the year (spring - summer - autumn - winter) allow for the probability curves of discharges $\mathrm{Qp}=\mathrm{f}(\mathrm{P})$ and $\mathrm{Qo}=\mathrm{f}(\mathrm{P})$ to be processed for individual months. To illustrate this, Fig. 3 presents the results of the analysis for four months, characterizing the seasons as follows: spring month - May, summer month - August, autumn month - November, and winter month - February. The results show the reservoir's vital functioning to ensure ecological discharges from the Ondava (Table 1). The overview of the results shows that summer and autumn are the most sensitive seasons due to the discharge fluctuations in the Ondava River upstream of the dam profile. In the spring and winter months, the natural reliability of discharge $\mathrm{P}$ for the specified optimal ecological discharge reaches $63-75 \%$. But in the summer and autumn the natural reliability of discharge $\mathrm{P}_{\alpha}$ is extremely low, i.e., less than $20-42 \%$. Without affecting the discharges from the Ondava through the Vel'ká Domaša reservoir, the river's ecological stability would be endangered in the summer and autumn with a probability higher than about $70 \%$ (about 130 days out of 184 days in the summer and autumn).

Tab. 1 Overview of the values of the natural reliability of the optimal ecological discharges from the Ondava River (1976 - 1997)

\begin{tabular}{|l|c|c|c|}
\hline \multirow{2}{*}{ Month } & $\begin{array}{c}\mathrm{P}_{\alpha}(\%) \\
\text { for } \mathrm{Q}_{\mathrm{opt}}\end{array}$ & $\begin{array}{c}\mathrm{P}_{\alpha}(\%) \\
\text { for } \mathrm{Q}_{\mathrm{opt}, \mathrm{red}}\end{array}$ & $\begin{array}{c}\mathrm{P}_{\alpha}(\%) \\
\text { for } \mathrm{Q}_{\mathrm{opt}, \mathrm{ws}}\end{array}$ \\
\cline { 2 - 4 } & $\begin{array}{c}\mathrm{H}_{\mathrm{v}} \geq 155 \mathrm{~m} \\
\text { a.s.1. }\end{array}$ & $\begin{array}{c}\mathrm{H}_{\mathrm{v}}<155 \mathrm{~m} \\
\text { a.s.1. }\end{array}$ & $\mathrm{H}_{\mathrm{v}}<152$ a.s.l. \\
\hline May (spring) & $\mathbf{6 3}$ & 90 & 92 \\
\hline August (summer) & $\mathbf{2 0}$ & - & - \\
\hline November (autumn) & $\mathbf{4 2}$ & 51 & 72 \\
\hline February (winter) & $\mathbf{7 5}$ & 78 & 84 \\
\hline
\end{tabular}

The reservoir's positive influence on the runoff can also be monitored through the values of $\mathrm{Q}_{\mathrm{p}}$ and $\mathrm{Q}_{\mathrm{o}}$ with a probability of occurrence of $90 \%$ and $95 \%$ (Fig. 4 ).

\section{$3.21998-2019$ period}

The inflows into and outflows from the reservoir in the period analyzed, as affected by climate change, are presented by the probability curves of exceedance of the average monthly discharges (Fig. 5).

Fig. 5 Probability curves of exceedance of the average monthly inflows and outflows at the Vel'ká Domaša dam(1998 - 2019)

From the $Q p=f(P)$ trends and $Q_{o}=f(P)$, where $Q_{p}$ is the inflow of water into the reservoir, $Q_{0}$ is the outflow from the reservoir, and $\mathrm{P}$ is the probability of occurrence, it is also possible to determine the natural reliability $\mathrm{P} \alpha$, corresponding to the optimal ecological flow, following the period analyzed of 1976-1997. The results document that climate change is evident in the hydrological series of 1998 2019. Compared to the $1976-1997$ period, it is possible to register not only greater inflow fluctuations, but also a significant decrease
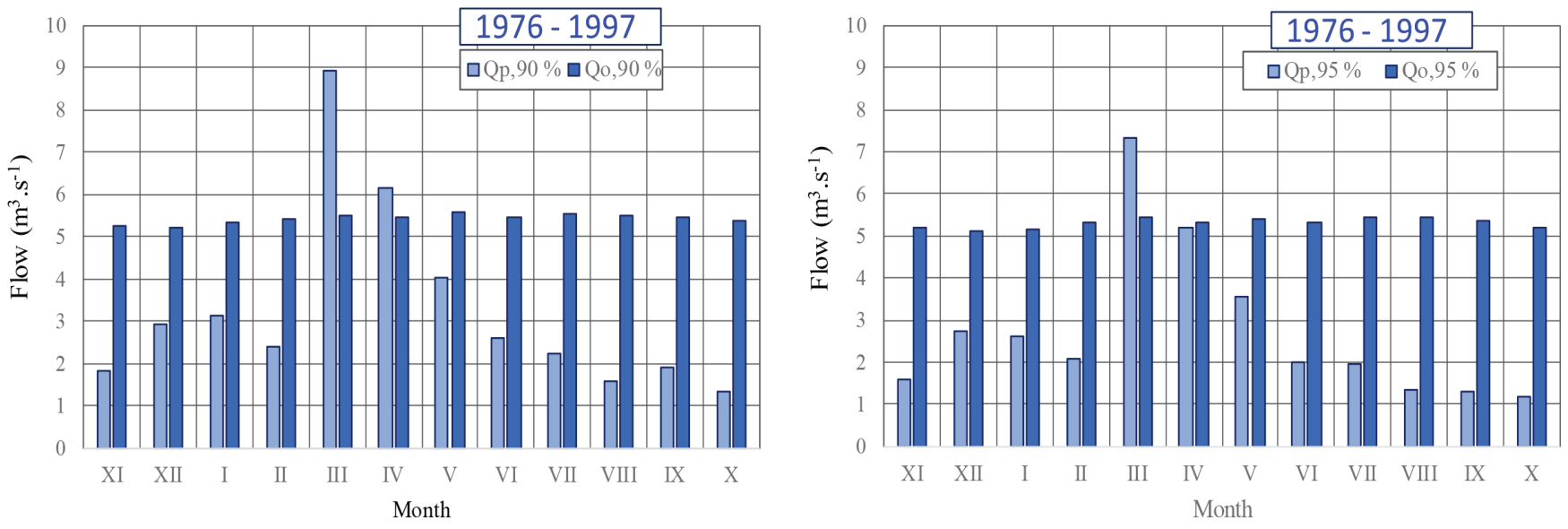

Fig. 4 Inflows to the reservoir $\left(Q_{p}\right)$ and outflows $\left(Q_{o}\right)$ in individual months (1976-1997) with the probability of occurrence of $90 \%$ and $95 \%$ 


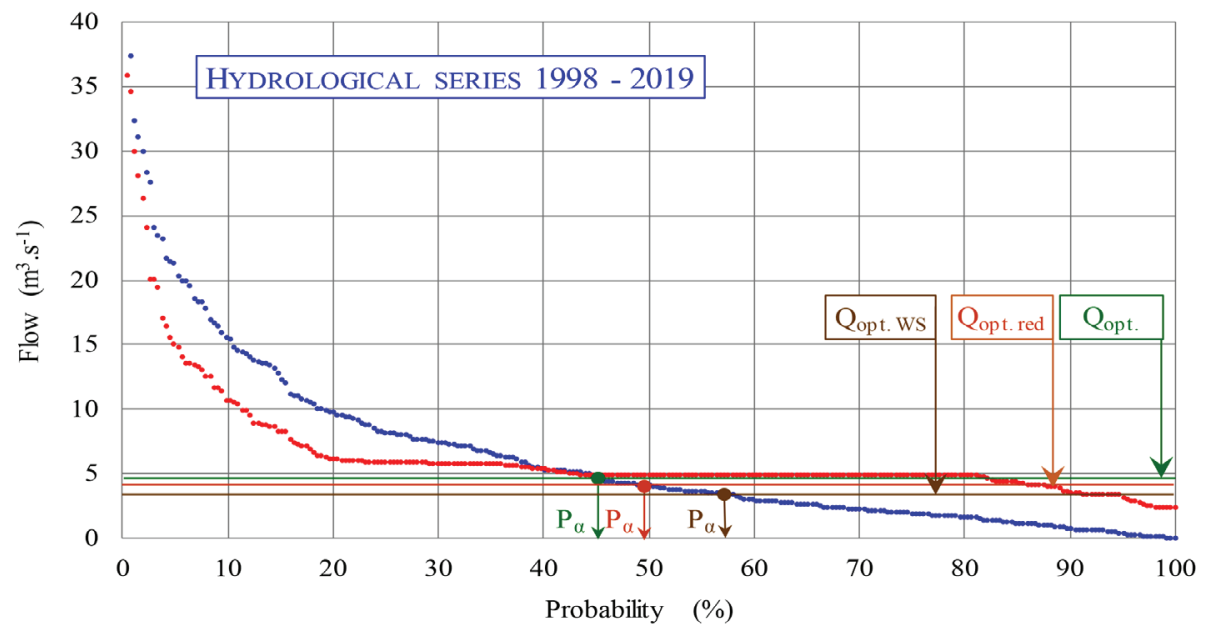

Fig. 5 Construction diagram of towers for Leitner monocable cableways with circulating system (authors)

in their long-term average from $6.5 \mathrm{~m}^{3} \cdot \mathrm{s}^{-1}(1976-1997)$ to $5.49 \mathrm{~m}^{3} \cdot \mathrm{s}^{-1}$ (1998 - 2019), which is reflected in the considerable reduction in the natural reliability $\mathrm{P}_{\alpha}$ of the optimal ecological discharge from the Ondava. Its value ranges from $45 \%$ to $57 \%$. Without the Vel'ká Domaša reservoir, the river's ecological stability would be endangered at a probability of about $50 \%$, which corresponds to 180 days a year. The vital functioning of the reservoir for ensuring ecological discharges is evident from the probability curves of exceedance of the inflows and outflows from the Ondava. It follows that the average monthly inflows into the reservoir higher than $5.0 \mathrm{~m}^{3} \cdot \mathrm{s}^{-1}$ with a probability of
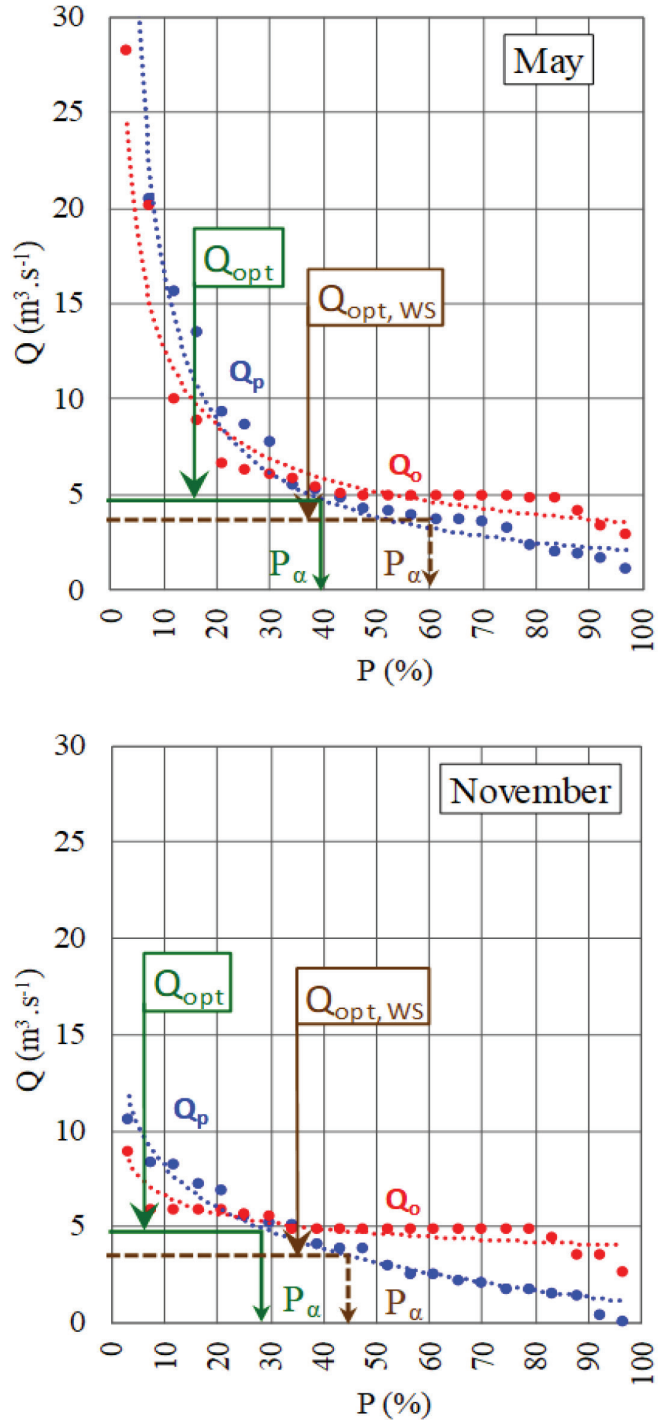
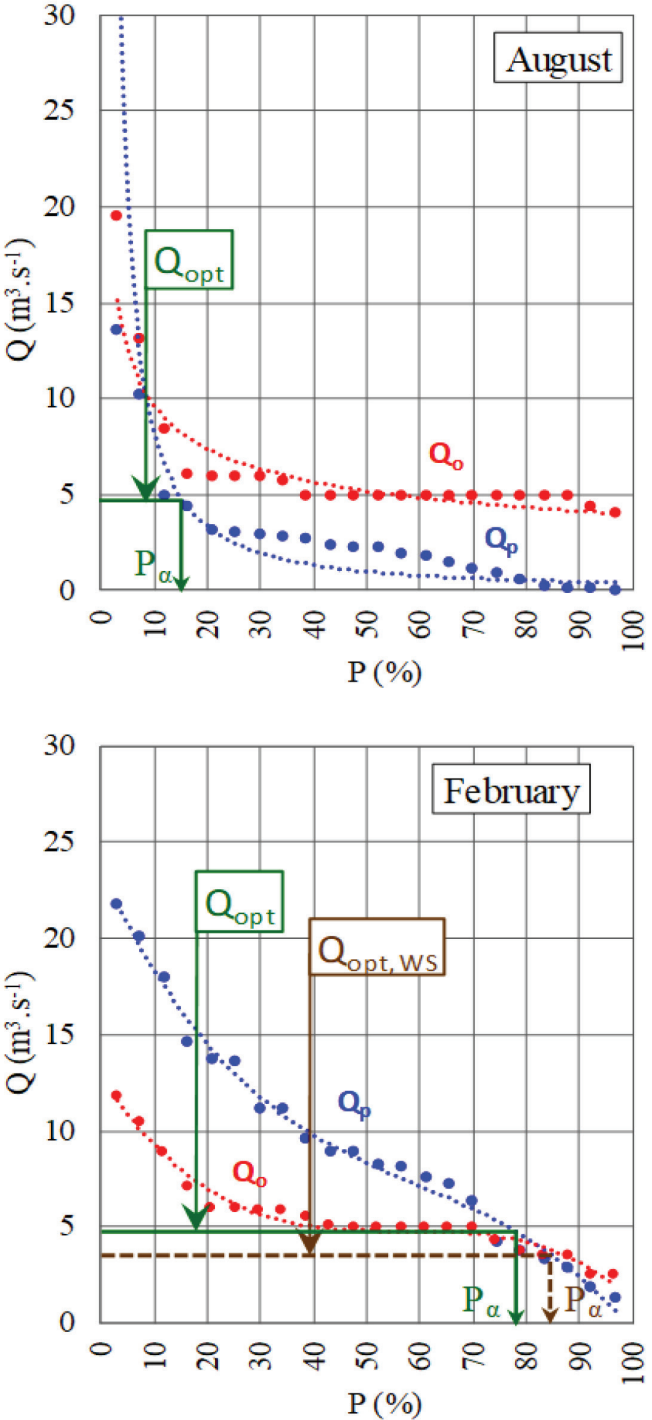

Fig. 6 Probability curves of exceedance of the average monthly inflows and outflows in selected months for the period of $1998-2019$ 
occurrence of about $40 \%$ were reduced, while inflows into the reservoir of less than $5.0 \mathrm{~m}^{3} \cdot \mathrm{s}^{-1}$ with a probability of occurrence of about $60 \%$ were improved to an average value of $5.0 \mathrm{~m}^{3} \cdot \mathrm{s}^{-1}$, and exceptionally (approximately in 18\%) less. The reservoir ensured the optimal ecological discharges in the area downstream of the dam.

The positive functioning of the reservoir for improving the runoff downstream of the dam during the year (spring - summer - autumn - winter) is confirmed by the probability curves of exceedance $\mathrm{Q}_{\mathrm{p}}=\mathrm{f}(\mathrm{P})$ and $\mathrm{Q}_{\mathrm{o}}=\mathrm{f}(\mathrm{P})$ processed for individual months. For illustration, we present in Fig. 6 the results of this analysis for four months by characterizing the different seasons as follows: spring month - May, summer month - August, autumn month - November, and winter month - February. The impact of the positive operations of the reservoir on the outflow conditions under the dam and their ecological stability is evident.

Tab. 2 Overview of the values of natural reliability of the optimal ecological discharges from the Ondava River (1998 - 2019)

\begin{tabular}{|l|c|c|c|}
\hline \multirow{2}{*}{ Month } & $\begin{array}{c}\mathrm{P}_{\alpha}(\%) \\
\text { for } \mathrm{Q}_{\mathrm{opt}}\end{array}$ & $\begin{array}{c}\mathrm{P}_{\alpha}(\%) \\
\text { for } \mathrm{Q}_{\mathrm{opt}, \text { red }}\end{array}$ & $\begin{array}{c}\mathrm{P}_{\alpha}(\%) \\
\text { for } \mathrm{Q}_{\mathrm{opt}, \mathrm{ws}}\end{array}$ \\
\cline { 2 - 4 } & $\begin{array}{c}\mathrm{H}_{\mathrm{v}} \geq 155 \mathrm{~m} \\
\text { a.s.1. }\end{array}$ & $\begin{array}{c}\mathrm{H}_{\mathrm{v}}<155 \mathrm{~m} \\
\text { a.s.1. }\end{array}$ & $\begin{array}{c}\mathrm{H}_{\mathrm{v}}<152 \mathrm{~m} \\
\text { a.s.1. }\end{array}$ \\
\hline May (spring) & $\mathbf{4 0}$ & 50 & 60 \\
\hline August (summer) & $\mathbf{1 5}$ & - & - \\
\hline $\begin{array}{l}\text { November (au- } \\
\text { tumn) }\end{array}$ & $\mathbf{2 8}$ & 34 & 45 \\
\hline February (winter) & $\mathbf{7 8}$ & 80 & 85 \\
\hline
\end{tabular}

The results documented show that the recorded changes in climate were reflected in the higher fluctuations of the Ondava discharges and their decreases. The most vulnerable periods are the summer and autumn months. In the spring and winter months, the natural reliability $\mathrm{P}_{\alpha}$ for the defined optimal ecological discharge reaches 40 to $60 \%$; in the summer and autumn months, this value is extremely low, i.e., less than 15 - 28\% (Table 2). Without affecting the discharge in the Ondava by the Vel'ká Domaša reservoir, the river's ecological stability would be endangered with a probability of more than approx. 80\% (approx. 150 days from the 184 days of summer and autumn periods). The positive influence of the reservoir on the discharge downstream of the dam can also be observed through the values of $\mathrm{Q}_{\mathrm{p}}$ and $\mathrm{Q}_{\mathrm{o}}$, with the probability of occurrence of $90 \%$ and $95 \%$ (Fig. 7 ).

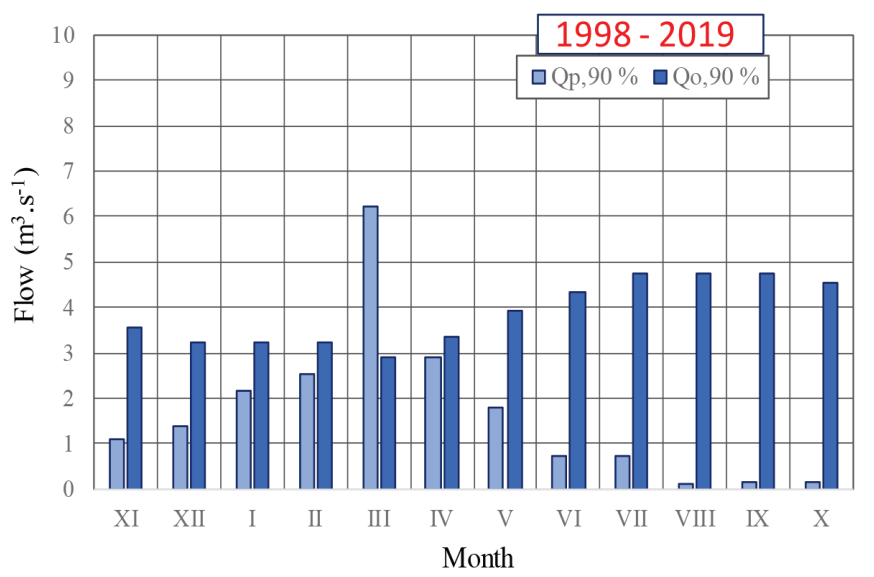

\section{CONCLUSIONS}

According to the demonstrated changes in the climate, hydrological extremes, and alternating short-term wet and long-lasting dry periods, the importance of water reservoirs is growing, especially reservoirs with multi-annual discharge regulation. The analysis of the discharges evidences the changes in the climate at the Vel'ká Domaša reservoir in two periods, i.e., before 1997 and after 1998. It follows that, due to the large fluctuations of the Ondava discharges, the ecological stability of the river would be endangered without the water reservoir, especially in the summer and autumn. It was proved that in the summer and autumn before 1997, the discharges were smaller than the optimal ecological discharges, i.e., about $60-80 \%$ of the time, and in the spring and winter, about $25-40 \%$ of the time. After 1998, this deficit deepened to a $70-85 \%$ probability of occurrence in the summer and autumn and $20-60 \%$ in the spring and winter. In addition to positively affecting the discharges in the riverbed downstream of the dam, the reservoir benefits the flood control and use of the river's hydropower potential. During its existence for more than 50 years, the Vel'ká Domaša artificial reservoir has become an integral part of the country, a recreational area, and an incentive from the development of tourism. Changes in the climate with long periods of drought have increased the requirements for ensuring optimal ecological discharges (affected discharges). A drop in the water level cannot be prevented when the inflows are smaller than the outflows, which is in disharmony with the requirements of entrepreneurs to maintain the maximum operating water level during the summer recreation season. However, the reservoir's primary functions are to improve discharges, flood control, and energy production. Suppression of the water management function of the reservoir without the use of its possibilities and capacities at the expense of providing recreational purposes is controversial. Such an approach threatens the full-fledged water management of the reservoir, reduces the degree of reliability of the flood control, increases the risk of endangering the river's ecological stability, and reduces use of the water for energy. This issue needs to be solved very sensitively. However, it would not be rational if the tertiary sector dictated the conditions for the operation of strategic objects in the primary water management sector.

\section{ACKNOWLEDGMENTS}

We would like to express our gratitude to the Slovak Hydrometeorological Institute and Slovak Water Management Enterprise for providing data and information. This paper is a part of the VEGA 1/0452/17 grant project funded by the Scientific Grant Agency of the Ministry of Education, Science, Research, and Sport of the Slovak Republic.

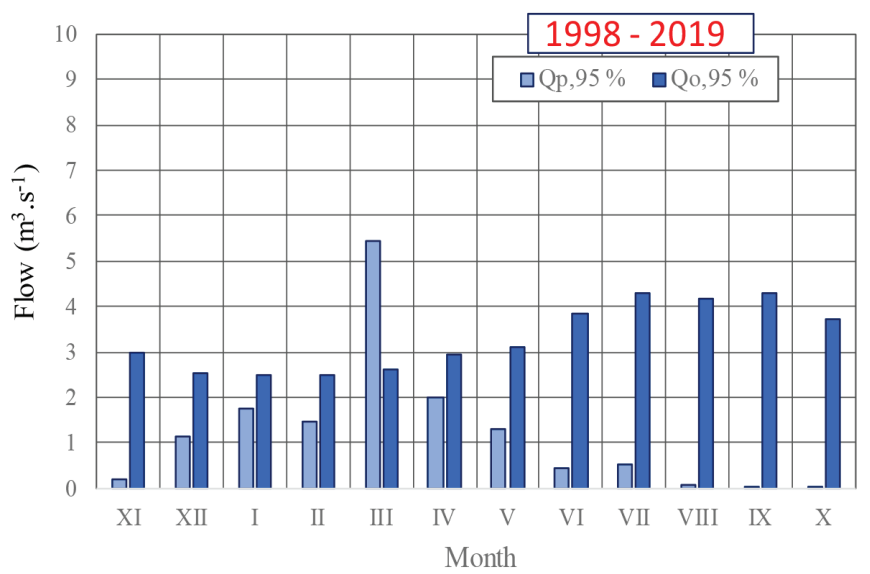

Fig. 7 Inflows to the reservoir $\left(Q_{p}\right)$ and outflows $\left(Q_{0}\right)$ in the individual months (2004 - 2019) with the probability of occurrence of $90 \%$ and $95 \%$ 


\section{REFERENCES}

Bednárová, E. - Lukáč, M. - Lukáč, M. - Minárik, M. Bakaljarová, M. - Lipták, B. - Miščík, M. - Panenka, P. Stoličný (2010) Dam construction in Slovakia. Originalities Milestones - Attractions. Bratislava, Kuskus 2010, 207 pp., ISBN 978-80-970428-0-6.

Benický, J. (2013) Velká Domaša: III. - Proposal of alternatives to operation regulations: VÚVH Bratislava.

Benický, J. (2013) Vel'ká Domaša - Analysis of the hydrological regime of water reservoir operation, Research paper, VÚVH Bratislava, $22 \mathrm{pp}$.
Benický, J. (2013) Vel'ká Domaša - Basic function of the reservoir after discharge improvements, Research paper, VÚVH Bratislava, 2013. $23 \mathrm{pp}$.

Lukáč, M. - Bednárová, E. (2001) Reservoirs and dams. Design and operation. ES STU, Bratislava, 330 pp.

Lukáč, M. - Bednárová, E. - Grambličková, D. - Mosný, V. (1997) Evaluation of the real operation of selected water reservoirs on the flow regime. Stage 2 VTP-4/VTP/5/97, SvF STU, 162 pp.

Votruba, L. - Patera, A (1997) Reservoirs and water management systems. ES ČVUT Prague, $191 \mathrm{pp}$. 